\title{
Fostering Fifth Graders' Reading Comprehension through the use of Intensive Reading in Physical Science*
}

\author{
La Comprensión de Lectura de Estudiantes de Quinto \\ Grado a través del uso de la Lectura en la Clase \\ de Ciencias
}

\author{
Alethia Paola Bogoya González \\ Fifth Grade Math Teacher \& Middle School Mathematics Curricular Assistant, \\ Colegio Rochester, Bogotá, Colombia \\ E-mail: abogoya@rochester.edu.co
}

\begin{abstract}
Reading comprehension in a content area needs to be seen from both the content and language perspectives. This paper examines the use of intensive reading, a strategy taken from the language teaching field, to help students improve their reading comprehension ability and develop understanding of science concepts. The study was carried out in a fifth grade class at a private bilingual institution of Bogotá. Reading was analyzed using a mixed-method approach that utilizes both qualitative and quantitative methods. The first method was done through students' interviews, artefacts, and a teacher's journal, and the second by means of two reading tests, Cloze and CARI, Content Area Reading Inventory Test. The statistical analysis shows that students improved their reading comprehension ability as their scores for the post-test were higher than those of the pre-test; this increment is statistically significant as $p \leq .05$ when applying a t-test. The qualitative analysis shows that structured reading practices lead to the development of students' cognitive processes. Overall, the results indicate that reading in science should be seen as dynamic process that incorporates learners' strategies in order to develop conceptual understanding.
\end{abstract}

Key Words: Content Area Reading, Reading Comprehension, Cognitive Processes, Science Instruction, Language Strategies

\section{Resumen}

La comprensión de lectura en una clase como ciencias físicas a través de una segunda lengua debe ser vista desde la perspectiva del contenido y el lenguaje. Este trabajo examina el uso de la estrategia lectura en detalle, una estrategia tomada de la enseñanza de la lengua, para ayudar a los estudiantes a mejorar su comprensión de lectura y comprender conceptos de la ciencia. El estudio fue realizado en una clase de quinto de primaria de un colegio bilingüe de la ciudad de Bogotá. Se utilizó un método de análisis mixto que tiene en cuenta tanto métodos cualitativos como cuantitativos. El primer método utilizó entrevistas a los estudiantes al igual que producciones en clase, y diario de campo del investigador y el segundo método, dos tipos de test de comprensión de lectura, Cloze y CARI - Test tipo Cuestionario para Áreas cuyo medio de instrucción es la segunda lengua. El análisis estadístico muestra que los estudiantes mejoraron su comprensión de lectura ya que los resultados para el post-test son mayores que aquellos del pre-test; este incremento es estadísticamente significativo, $p \leq .05$ una vez que la prueba-t es aplicada a los datos. Por otra parte, el análisis cualitativo muestra que prácticas estructuradas de lectura conllevan al desarrollo de procesos cognitivos por parte del estudiante. En general los resultados indican que la lectura en ciencias debe ser vista como un proceso dinámico que tiene en cuenta las estrategias de los estudiantes para desarrollar comprensión de conceptos.

Palabras clave: Comprensión de lectura, procesos cognitivos, enseñanza de la ciencia, estrategias de lenguaje.

Received 12-Dec-2010/ Accepted 10-May-2011

* Research Article associated with "Intensive Reading: a Strategy to Foster Students' Reading Comprehension of Science Texts within a CLIL approach". This report was submitted for the degree of Master in English Language Teaching - Autonomous Learning Environments, Universidad de La Sabana, Bogotá, Colombia. 


\section{Introduction}

Reading comprehension has always been a cornerstone of successful academic projects. As Hedgcock \& Ferris (2009) argue, "few question the fundamental notion that reading is a crucial building block" (p.2) of success in academic and labor environments. Content area teachers cannot overlook this fact and must undertake the challenge of addressing reading from the language and content perspective to guarantee the development of both thinking and language processes. Content and Language Integrated Learning (CLIL) emerges as a feasible approach that facilitates such integration in the context of learning an additional language. "In short, CLIL is a dual-focused educational approach in which an additional language is used for the learning and teaching of both content and language" (Mehisto, P., Marsh, D., \& Frigols, M., 2008, p. 9).

This paper examines the use of intensive reading, a strategy taken from the language teaching field, to help students understand science concepts and improve their reading comprehension ability. The research question posed was: How can the implementation of intensive reading skills help fifth grade students to decipher information in a science contentbased class?

The study was carried out with a fifth-grade class who were taking for the first time a contentbased subject called physical science. By the end of the school year, these learners are expected to comprehend a variety of concepts such as eclipses, types of energy, and mechanical waves, among others. Since this early stage of their science studies corresponds to conceptualization; students need to describe, explain, and illustrate the topics aforementioned as a result of a variety of learning experiences derived from reading their textbooks. Therefore, the ability to effectively read is undoubtedly central to success at the end of the school term.
During the first academic term, students struggled with constructing meaning and they copied or said the exact words appearing in the textbook. Even though this corresponds to a literal reading comprehension level, at the institution where the study took place students should develop skills at the inferential and critical reading comprehension levels.

Several factors might explain the situation described above: a) students' language level, b) students' lack of knowledge regarding how to read science texts, and c) the alignment between learners' needs, the relevance and authenticity of the materials used, and the instructional design of the lessons.

Therefore, an action research project aimed at helping students understand what they had to read as well as fostering a new reading perspective within the class was needed. Hence, a series of reading activities were developed around the concept of intensive reading to give students a set of strategies for them to interact with the text, make the most of it, and construct knowledge.

\section{Theoretical considerations}

Three main concepts emerge after analyzing the research question: CLIL, intensive reading, and deciphering information. CLIL methodology entails the use of different language strategies, i.e. intensive reading, to foster learners' development of both language and content skills. In addition, under the CLIL framework, cognition emerges as a relevant component of effective instruction. In this regard, the Information Processing Theory which explains what deciphering entails may support the CLIL teacher in terms of planning activities addressed to organize and re-elaborate information when helping learners understand a text.

\section{CLIL}

As mentioned earlier, CLIL offers a framework of reference for language and content 
teachers. In this regard, Snow, Met and Genesee (1989) provide solid arguments in favor of integrating content and language teaching; these authors argue that "content provides a primary motivational incentive for language learning insofar as it is interesting and of some value to the learner and therefore worth learning. Language then will be learned because it provides access to content, and language learning may even become incidental to learning about the content" (p.202). The teacher's role constitutes another important aspect to take into account under this framework; as Snow, et al. (1989) argue, under the immersion class scenery, the case of bilingual schools, the teacher "plays the roles of the content teacher teaching subject matter and the language teacher seeking out opportunities to maximize language development" (p.211). This fusion of roles requires teachers to plan "consciously for language growth as an integral part of content instruction" (p.214).

Therefore, the content teacher needs to carefully plan his/her lessons, draw on fellow language teachers' expertise, and analyze learners' linguistic and academic needs and skills to guarantee that students, by the end of a lesson, master not only the concepts of the content area but also effectively communicate using the target language. In addition, Coyle (2005) develops what is known as the 4C's framework: Content, Communication, Cognition, and Culture, to help teachers systematically plan a lesson that fulfills content and language requirements.

In terms of reading, Goodman (1996, p. 21) mentions that "if we want to understand the written language, we should put together the knowledge coming from different disciplines" to point out the need to combine different perspectives when teaching reading.

Eskey (2005) defines reading comprehension as an experience that involves the reader's emotions, beliefs, and thoughts resulting not only from the reader's individual characteristics but also his/her experience. This prior knowledge the reader brings to the text includes, as Atorresi (2009) affirms, linguistic knowledge such as syntax, vocabulary, and sentence structure. Therefore, the reader needs to activate different types of knowledge as $\mathrm{s} /$ he reads a text to negotiate and construct meaning. Navarro (1987) views this process as a cognitive one because the reader compares and contrasts not only two different linguistic and semantic networks but also two mental organizations (schemata). Finally, Goodman (1996) emphasizes the active nature of reading: "the writer produces a text to convey meaning; but the text is never a complete transmission of such meaning the writer wants to convey...the meaning is within the reader and the writer, it is not within the text...the effectiveness of the reading process consists in getting the meaning out of the printed codes, nor in correctly identifying a word." (p. 12).

As shown, there is an increasing agreement about seeing reading as a process that goes beyond printed codes (Eskey, 2005; Chavez, 1987; Navarro, 1987; Goodman, 1996).

Finally, in relation to reading assessments Goodman (1996) highlights the fact that understanding should result from reading a text. Teachers and researchers focus on understanding as a product rather than a process when the objective is measuring reading. However, this does not imply, as Brown (2004) asserts, that the teacher focus just on the tests' results. Getting to know the strategies students used to approach a text and helping learners see their effectiveness is important as well. For the purposes of this study where reading is seen as a process that entails negotiation, Brown (2004, p. 201-215) recommends, among the different procedures, "cloze tasks" and "impromptu reading plus comprehension questions". 


\section{Intensive Reading}

According to Nation (2004), "intensive reading involves the detailed reading of texts with the two goals of understanding the text and learning language features through a deliberate focus on these items" (p. 20). The text chosen implies difficulty for the reader due to the content or the language, i.e. unfamiliar grammar or vocabulary. Hedgcock, et al. (2009) mention the following significant features of intensive reading:

- The teacher selects the texts to be studied, introduces, and reinforces certain reading strategies by means of whole-class instruction and student activities.

- Students read the same text at the same pace and complete several exercises that facilitate understanding.

- Teacher and students have clarity about what to do before, during, and after reading.

- Pre-reading activities are decisive to facilitate comprehension. These activities include surveying the text, making predictions, asking questions, and introducing key vocabulary.

- While-reading activities include first reading, a "quick read-through the entire text to develop a sense of its main point(s) and to confirm initial predictions made during pre-reading (p. 172)", re-reading the text: "read the text intensively through a careful and focused second reading (p. 172)", looking closely at language, and considering the structure of the text.

- Post-reading activities entail summarizing and responding, thinking critically, and readingwriting connections. "Post-reading activities also offer the best opportunities for teacher assessment of student progress, as they make the internal reading process and its outcomes more transparent" (p. 185).

\section{Deciphering Information}

As stated at the beginning of this paper, students had difficulty understanding a text beyond the literal level. Understanding entails deciphering the information in such a way that students give their own accurate and precise interpretation of the phenomenon under study. Cognitive models "view learning as an active, dynamic process in which learners select from incoming information, encode it into long-term memory, and retrieve it when needed" (Chamot, 1999, p. 157). The Information Processing Theory developed by Gagné (1985) mentions that learning processes take place when the learner modifies the input (new information) and stores it in what is called the short-termmemory (STM) by relating the input to already existing information. Then, the learner codifies the information using different strategies such as reviewing, elaborating, and organizing the data (i.e., by means of graphic organizers) so this input is placed into the long-term-memory (LTM). As a result, students will be able to communicate verbally or in written form what a concept means.

\section{Methodology}

This research study was carried out at a private bilingual institution of Bogota. Twentyseven males and females between 10 and 12 years old of an intermediate English level participated in this study. They have the subject, physical science, twice a week, for one hour per class.

The class is a mixture of visual, verbal, and logical learners according to a learning style inventory students filled out at the beginning of the project. Some learners still depend on the teacher to verify if what they understood is accurate or not and so they appreciate the teacher's support as they go through each of the activities proposed during the class. Learners are using the textbook McDougal Littell Science I. The book provides lots of readings adjusted to middle school learners; however, as the book is imported, second language learners need to 
develop a set of reading strategies that help them read effectively.

\section{Type of Study}

This study corresponds to a small-scale intervention with the purpose of analyzing the impact, benefits, and positive or negative outcomes of that intervention in a given population. Taking into consideration that it involves seeking learning strategies within the context of the classroom, and that the ultimate goal is no other than changing the teaching practice, action research represents the most appropriate type of research for this study.

\section{Data Collection Instruments}

When deciding on the data collection tools, the researcher needs to keep in mind the issue of validity and reliability. The former "refers to the degree to which scientific observations actually measure or record what they purport to measure" (Pelto \& Pelto, cited by Mills, 1999, p.84); the latter to the precision of the data. Triangulation then becomes the "best known way of checking for validity" (Burns, 2010, p. 163). Sagor (2005) agrees with the claims made by Burns (2010) and Mills (1999) and advises the researcher to use a triangulation matrix so corroboration of findings will be assured as different independent pieces of information point in the same direction. Table 1 below describes the triangulation matrix used in this study.

Table 1. Triangulation Matrix according to Sagor (2005)

\begin{tabular}{|l|l|}
\hline \multicolumn{1}{|c|}{ QUESTION } & \multicolumn{1}{|c|}{ DATA COLLECTION INSTRUMENTS } \\
\hline Research Question & Source 1: students' artefacts; \\
How can the implementation of intensive reading skills & Source 2: students' final interview; \\
help fifth grade students to decipher information in a & Source 3: teacher's research journal; \\
science content-based class? & Source 4: students' tests. \\
\hline
\end{tabular}

Artefacts. According to Lankshear et al (2004) artefacts correspond to physical and concrete evidence of what the participants carry out within their context. Among the different artefacts students developed, two are of particular interest, the graphic organizers (appendix A) and the students' summaries done after reading a given science text. The graphic organizers merge both the language and the content by explicitly giving the students the key vocabulary of the text and asking them some questions to challenge their thinking and favor conceptual development. These graphic organizers were used as a postreading activity to help students and the teacher evaluate reading comprehension.
- Interviews. A final interview was done with the purpose of informing the researcher about students' insights regarding the project itself, concepts and reading strategies they learned, and further recommendations. The semistructured type was chosen (Burns, 1999) since the researcher might talk about emerging topics as the conversation flows.

- Teacher's Research Journal. Teacher's perceptions about students' reading process and elements positively or negatively affecting it were systematically collected. In addition, conversations held through Skype with the research director informed the research journal as well. In action research, Skype-Logs as 
data collection tools have great potential since they can be used, as here in this study, as evidence of the ongoing reflection process that characterizes this type of research.

- Students' Tests. Two types of tests were used to quantitatively measure students' progress: a cloze test (refer to Appendix B) and a Content Area Reading Inventory Test - CARI (refer to Appendix C). Both the pre-test and post-test correspond to different instruments that follow, nevertheless, the structure and guidelines proposed by Chatel (2001) and Sejnost (2007). Once the results of the cloze tests have been analyzed, according to Chatel (2001), students can be placed within three levels: independent reading level (58 to $100 \%$ ), instructional reading level (44 to 57\%), and frustration reading level (0 to $43 \%$ ). These percentages are calculated as total number of correct responses over total number of questions. Table 2 describes each one of these levels.

Table 2. Reading Levels resulting from analyzing the Cloze Test according to Chatel (2001) and Sejnost (2007)

\begin{tabular}{|c|l|}
\hline \multicolumn{1}{|c|}{ READING LEVEL } & \multicolumn{1}{c|}{ DESCRIPTION } \\
\hline Independent & $\begin{array}{l}\text { The learner reads the text without teacher's support and s/he successfully accounts for } \\
\text { what the text explains. }\end{array}$ \\
\hline Instructional & $\begin{array}{l}\text { The learner finds the text challenging but not "out of reach". S/he can manage text if } \\
\text { appropriate instruction is delivered. }\end{array}$ \\
\hline Frustration & $\begin{array}{l}\text { The learner cannot construct meaning out of a text. It is beyond his/her ability. The teacher } \\
\text { needs to offer lots of support and guidance. }\end{array}$ \\
\hline
\end{tabular}

\section{Results}

A mixed-method approach (Creswell, 2003) was chosen to analyze the information since this study pursues both quantitative and qualitative aims. This approach consisted of a) measuring reading comprehension as a result of implementing intensive reading practices and b) identifying key elements when implementing reading in content-based classes. Therefore, the combination of both quantitative and qualitative methods provided the researcher with different perspectives that nurture the analysis and make it more valid since triangulation methods are taken into account. The main tools for analyzing and synthesizing qualitative data correspond to categorizing (Burns, 2010), which implies sorting objects into logical groups and developing a well-structured theoretical framework that explains the phenomena under study. Descriptive and inferential statistics are used for analyzing quantitative data. Table 3 outlines the type of analysis to be followed. 
Table 3 Data Analysis Methods followed during this study

\begin{tabular}{|l|l|l|}
\hline \multicolumn{1}{|c|}{ DATA COLLECTION INSTRUMENT } & \multicolumn{1}{|c|}{$\begin{array}{c}\text { NATURE } \\
\text { OF DATA }\end{array}$} & \multicolumn{1}{|c|}{ ANALYSIS METHOD } \\
\hline Teachers' Journal \& Skype Logs & Qualitative & \multirow{2}{*}{ Categorizing } \\
\hline Interviews & Qualitative & \\
\hline Students' tests & Quantitative & Descriptive and Inferential Statistics \\
\hline $\begin{array}{l}\text { Students' artefacts (graphic organizers, short summaries, } \\
\text { and reflections) }\end{array}$ & Qualitative & Categorizing \\
\cline { 2 - 3 } & Quantitative & Descriptive and Inferential Statistics \\
\hline
\end{tabular}

In relation to categorizing, this study follows the guidelines proposed by Auerbach (2003) who advises a six-step analysis procedure that consists of recording repeating ideas, grouping them, forming categories, developing theoretical constructs, and creating a theoretical narrative.

On the other hand, the quantitative analysis is based on the students' scores for both cloze and CARI tests. The pre-test results were compared against the pos-test results by using both descriptive and inferential statistics. As no control group was used, this study also relies on the nonparametric item response theory (NIRT) in order to provide theoretical foundation to the conclusions derived from the statistical analysis. "In general, the IRT reflects the notion that the higher the latent trait value $\theta$, the higher the probability of correctly answering an item that measures $\theta$...NIRT models assume that the relationship between P: $(\theta)$ and $\theta$ is governed by order restrictions" (Sijtsma E Molenaar, 2002, p. 14). In other words, the student's ordinal position on one test should be similar to the corresponding ordinal position on the second test given that the two tests measure the same construct due to the fact that the relationship between the student's ability and the test difficulty is similar for the two tests.
Finally, both quantitative and qualitative analysis were interwoven in order to find common trends that can be grouped as categories, which later will retell the story of what happened, how, and why.

\section{Quantitative Analysis}

The statistical analysis was conducted using SPSS; the results show that a large number of students improved their reading comprehension as their scores for the post-test are higher than those of the pre-test for both the CARI test and the cloze test. On average, students got twenty points more in the post-test, on a scale from 0 to 100 , this increment being statistically significant, $p \leq .05$.

Figure 1 below shows a box-and-whisker plot that informs how the students' scores in the CARI test and cloze test have improved and the variability among the data has diminished. These results are significant since overall class success is determined by having both a high score and a low dispersion. In addition, table 4 summarizes the descriptive statistics for both tests considering what happened before the implementation (prestage) and after the implementation (post-stage). 
Table 4. CARI Test and Cloze Test Descriptive Statistics

\begin{tabular}{|l|c|c|c|c|}
\hline \multicolumn{1}{|c|}{ TEST } & \multicolumn{2}{c|}{ CARI } & \multicolumn{2}{c|}{ CLOZE } \\
\hline Stage & pre & post & pre & post \\
\hline Mean & $\begin{array}{c}47 \\
{[35,59]}\end{array}$ & $\begin{array}{c}68 \\
{[60,77]}\end{array}$ & $\begin{array}{c}47 \\
{[37,56]}\end{array}$ & $\begin{array}{c}63 \\
{[56,70]}\end{array}$ \\
\hline Median & 56 & 78 & 50 & 67 \\
\hline Standard Deviation & 29 & 21 & 24 & 17 \\
\hline
\end{tabular}

In addition, inferential statistics were used to determine if the difference reported between the two means for both types of tests was statistically significant. To do so, a matched-pair sample t-test was conducted. For both the CARI and cloze tests, $\mathrm{p} \leq .05$, which indicates that the average post-score significantly exceeded the average pre-score.

Finally, correlations between the Cloze and CARI test results were established in order to add to the ongoing controversy of whether the cloze procedure could be used as a valid indicator for measuring reading comprehension. When a correlation between two variables is established, the researcher can assert that there is a relationship between them (if one variable changes, then the other will change as well).

- Pre-tests. According to the results yielded by SPSS there is a significant relationship between these two tests. The Pearson coefficient equals

Note. Values in brackets correspond to the lower limit and upper limit of a 95\% Confidence Interval.
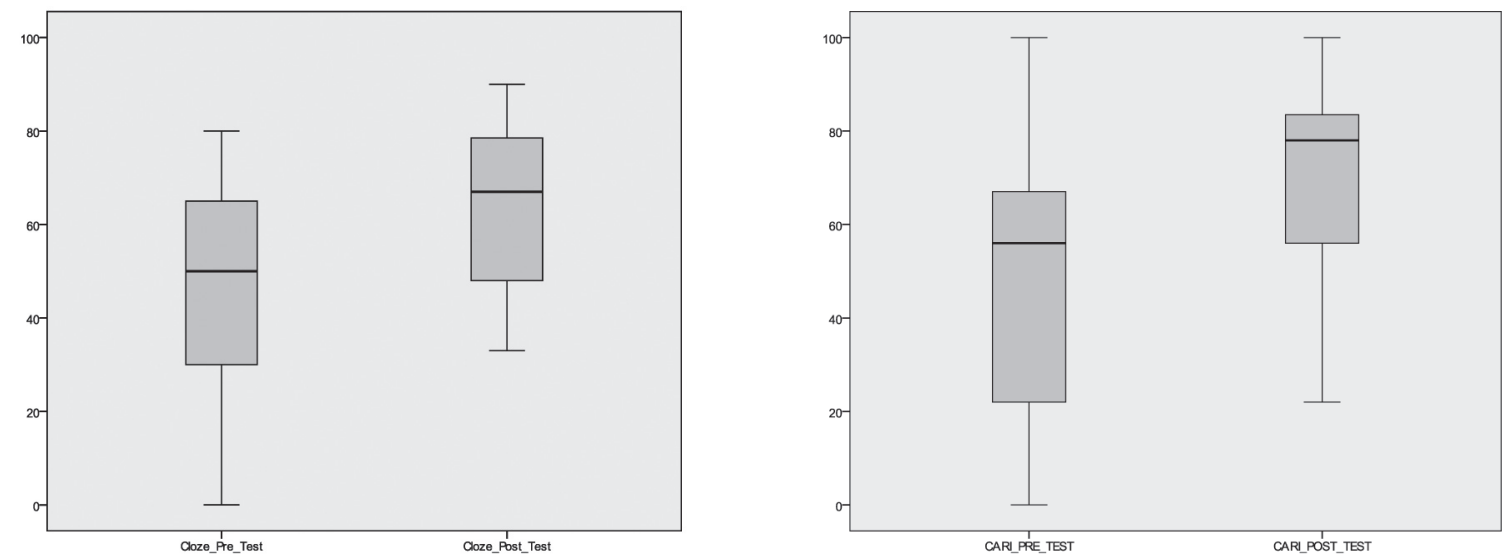

Figure 1. Box-and-whisker plots for both the CARI and cloze tests, respectively. A box-and-whisker plot shows the data distribution by finding out five statistical values: minimum, first quartile, second quartile (median), third quartile, and maximum. The minimum and maximum values give the researcher the range of the data. CARI test: the pre-test shows that students' scores lie between 0 and 100, while the post-test shows that students' scores lie between 22 and 100. Cloze test: the pre-test shows that students' scores lie between 0 and 80, while the post-test shows that students' scores lie between 33 and 90. These results indicate that the difference between the low and high achievers is being shortened. In addition, the second quartile (the line that falls within the box) shows the middle of the distribution. For the cloze test, the pre-test value corresponds to 56 and the post-test value to 78 ; whereas, for the CARI test, the pre-test value equals to 50 and the post-test value to 67 . This indicates that half of the data is between 0 and the second quartile, and the other half of the data is between the second quartile and 100. Students' scores are improving and students performed better after the implementation was carried out. As none of the students gets $100 \%$ in the cloze test, its difficulty is evident, even though students have shown according to the CARI tests that fully comprehension can be achieved. 
0.733, when two-tailed critical value equals to 0 with an alpha significance level equal to 0.05. The correlation coefficient corresponds to a statistical value, ranging from negative one $(-1)$ to positive one (1), which describes relationships between two sets of data. The closer this coefficient gets to 1 or -1 , the stronger the relationship between the two variables.

- Post-tests. A positive significant relationship between these two tests is maintained although the Pearson Coefficient decreases to 0.539, when the two-tailed critical value is 0.008 with an alpha significance level equal to 0.05 .

\section{Students' Reading Level According to the Cloze Test}

According to Chatel (2001) cloze tests allow the researcher to identify three reading levels (independent, instructional, and frustration) depending on the percentage of correct responses. The graph below shows the percentage of students within each level before and after the intervention. The number of students at frustration level decreased by $50 \%$, while the number of students at instructional and independent levels increased by $150 \%$ and $30 \%$ respectively.

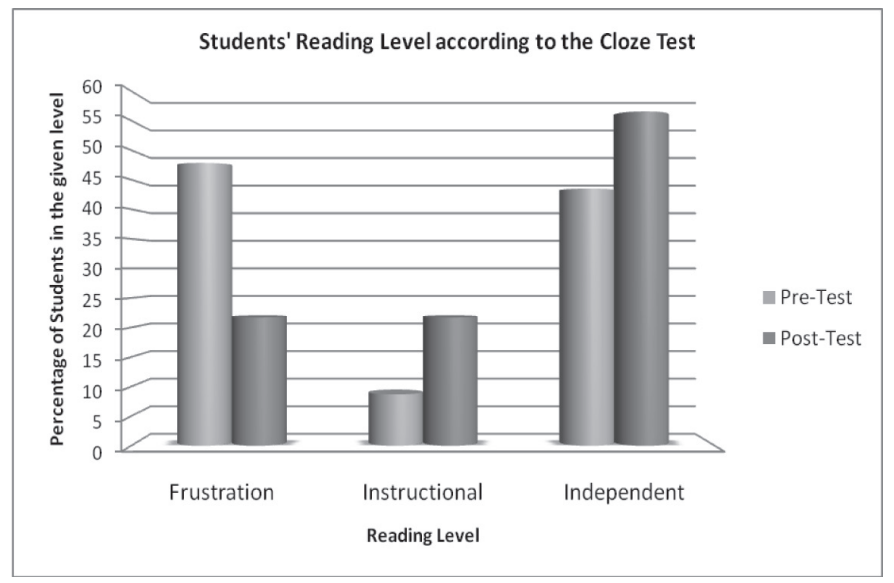

Figure 2. Percentage of students in each reading level, before and after the implementation.

\section{Interpreting the Quantitative Results}

There is a positive relationship between the cloze test results and the CARI test results, which means that if a person's test result is located in a given ordinal position (Molenaar, 2002) on any of the tests, i.e. student 1 has been placed within the first quartile, s/he has a very high probability of maintaining the same ordinal position on the other test ${ }^{1}$. In fact, according to the results of this study, there is a $96 \%$ probability that a student scoring below the mean for the cloze pre-test will be placed below the mean when $s /$ he takes the CARI test; whereas this probability decreases to $75 \%$ for the post-stage.

This shows that the correlation between these two types of tests weakens from the prestage to the post-stage. Learners whose reading level, according to the cloze test, corresponds to frustration (below $43 \%$ of correct responses) during the post-stage might achieve competent

1 Sijtsma \& Molennar (2002), among other authors, have proposed the nonparametric item response theory in order to explain the close relationship between the results of two different tests when they assess the same construct but with different strategies. The two mentioned strategies could be for example, in the case of reading assessment, on one hand the linguistic competence (cloze test), and on the other hand the communicative competence (CARI test). It is clear that 
results on the CARI test. If the cloze test determines a linguistic ability, this result might indicate that under the CLIL framework learners who begin the intervention with a low linguistic ability might improve their reading comprehension ability. That means the intervention carried out favors students' reading because of the different strategies used beyond the linguistic competence.

If the Pearson coefficient ( $r$ ) is squared and written as a percentage, pre-stage $=54 \%$, post-stage $=29 \%$, it can be concluded that $54 \%$ of the variability observed in the CARI test can be explained by the results on the cloze test during the pre-stage. On the other hand, 29\% of the variability observed in the CARI test can be explained by the results on the cloze test during the post-stage. This information might indicate that due to the intervention, other variables besides linguistic ability appeared as key factors contributing to the students' reading comprehension level in a content area. These other variables could be students' motivation, awareness of different reading strategies that allow learners to deepen the reading comprehension field and learners' systematic training.

Therefore, reading should be assessed from different perspectives. The linguistic competence, even though it facilitates content acquisition, is not the only variable that should be taken into account. The data highlights that learners' strategies are at the core of successful reading practices.

\section{Qualitative Results}

The teacher's journal and Skype logs show the complexity of the phenomenon under

these two approaches are different; however, they share the same construct that is reading comprehension. Nevertheless, the reader should bear in mind that when the two approaches start to get apart in the semantic field, the relationship weakens. For instance, if one test assesses the linguistic competence at the level of literal reading, and the other test assesses the communicative competence at the level of critical inter-textual reading, the relationship will start to fade out. study, as many elements should be in place so that students develop reading comprehension skills that result in understanding scientific concepts. The qualitative coding reveals two main categories:

Reading as a process that entails different dimensions. When implementing reading practices in the classroom, the teacher needs to be aware of how to measure it, how to articulate it within the lesson plan, how to find a balance between individual and social approximations to the text, and how to help students decipher printed codes. Throughout the process measuring reading was a key component; the following excerpt from the teachers' journal "Reading is such an invisible process that I am not sure how to observe it during the class" (week 1, April 14th) evidences the extent to which the researcher needs to make decisions about how to observe and make inferences regarding the processes students undergo as they read. The second element has to do with this excerpt from the Skype-log: "however way you go, it's important to have pre and post reading activities" (week 3, May 5th, expert researcher comment). This implies that reading can no longer be reduced to reading a textbook and answering the questions at the end of the chapter; reading needs to be seen as a dynamic endeavor that promotes a students' active role. In other words, reading needs to be seen as a flexible, interactive, and reflective process.

The third element and probably most significant takes into account the tension that exists between reading as a personal process and reading as a process mediated by interactions among learners. The following excerpts illustrate this tension.

"...students felt this need to talk to others and shared what they have learned or asked questions to their peers" (teacher's journal, week 2, April 28th). 
"...some students prefer to work on their own, reading for some is an individual act" (teachers' journal, week 3, May 7th).

"I think there is a cultural dimension which should not be ignored and could actually be used to the advantage of learning" (skype-log, week 3, May 5th, expert researcher comment).

Finally, reading should be seen as an input that needs to be deciphered. Just reading will not guarantee an understanding of the scientific concepts. It is the teacher's responsibility to promote different activities before and after students read a given text (i.e. sharing in pairs, making a summary, asking questions, listening to the teachers' point of view). The following excerpts affirm the previous points:

“...students seem to finally understand what PE is about. Of course, working with others is helping them strengthening their knowledge" (teacher's journal, week 3) "Students need to find connections between what they saw previous classes and what they are about to study" (teacher's journal, week 2 \& 4)

\section{Promoting conceptual understanding}

When teaching a content subject, the teacher cannot overlook the fact that the main goal is to achieve conceptual understanding. Grounding concepts, fostering cognition, and moving from factual knowledge to conceptual knowledge is vital in science classes.

"There are some physics concepts that call for a very practical point of view, I mean you as a teacher know if the students had understood the concept when they are able to explain it using real life examples" (teacher's journal, week 3).

The semi-structured interview results confirm the appropriateness of the three reading levels identified by Chatel (2001); independent, instructional, and frustration. Table 5 below summarizes the main descriptors of each reading level. Identifying students' reading level is crucial in order to guide the learning process in terms of learners' needs. We know now that each student learns differently; therefore, each student should be given specific strategies to improve his/ her performance. Each reading level needs to be clearly defined so the teacher can use that information to make professional decisions regarding how to help a student.

Table 5 Characterization of the three reading levels: Independent, Instructional, E Frustration

\begin{tabular}{|c|c|c|c|}
\hline READING LEVEL & INDEPENDENT & INSTRUCTIONAL & FRUSTRATION \\
\hline $\begin{array}{c}\text { Content } \\
\text { Development }\end{array}$ & $\begin{array}{l}\text { Students are able to accurately describe } \\
\text { a concept } \\
\text { "Well, a wave is a disturbance that is cre- } \\
\text { ated by two forces push and pull, it travels } \\
\text { through a medium, must travel through a } \\
\text { medium: that can be water, air, or a solid } \\
\text { object" (student 3) }\end{array}$ & $\begin{array}{l}\text { Students try to explain a concept, but } \\
\text { lack accuracy } \\
\text { "The last one that was about waves, } \\
\text { one is electromagnetic that is a } \\
\text { disturbance that moves through a } \\
\text { field and a field is like an object, } \\
\text { space, and how can we find a wave" } \\
\text { (student 9) }\end{array}$ & $\begin{array}{l}\text { Students are unable to explain a } \\
\text { concept or just do not remember } \\
\text { "I don't know it" } \\
\text { (student 1) }\end{array}$ \\
\hline $\begin{array}{c}\text { Awareness of reading } \\
\text { strategies }\end{array}$ & $\begin{array}{l}\text { Students have an ample range of reading } \\
\text { strategies } \\
\text { "Yes, for example to read the first sentence } \\
\text { in the paragraph and the last sentence to } \\
\text { know what the paragraph is about, and } \\
\text { focus in the question so that I know what } \\
\text { to answer, and sometimes to underline } \\
\text { important words that will help me } \\
\text { understand the text" (student12) }\end{array}$ & $\begin{array}{l}\text { Students have a limited number of } \\
\text { strategies and seem to repeat } \\
\text { ineffective ones } \\
\text { "To read more than once time the } \\
\text { papers, to read it and one more time, } \\
\text { and one more time to understand and } \\
\text { understand } \\
\text { and to take many notes, it is very } \\
\text { important"(student } 7 \text { ) }\end{array}$ & $\begin{array}{l}\text { Students do not recognize a } \\
\text { strategy or repeat ineffective } \\
\text { ones } \\
\text { "Read carefully if you don't } \\
\text { understand and repeat and } \\
\text { repeat to understand" } \\
\text { (student 10) }\end{array}$ \\
\hline
\end{tabular}




\section{Interviewing both Quantitative and Qualitative Analysis}

What both the quantitative and qualitative analysis reveal about reading comprehension and conceptual development is shown in Figure 3. Students, in fact, develop understanding in science classes through reading. When in this process, both teacher and learners use effective strategies. During this study, students highlighted important information, took notes, wrote summaries, shared ideas with each other, and provided examples. These strategies helped them become aware of their reading process and moved them towards an independent reading level. In terms of teachers' strategies, the coding shows that scaffolding (eliciting key vocabulary, questioning, pairing students according to their reading level, and modeling), listening to the students' ideas, and being a reflective practitioner positively impact students' performance.

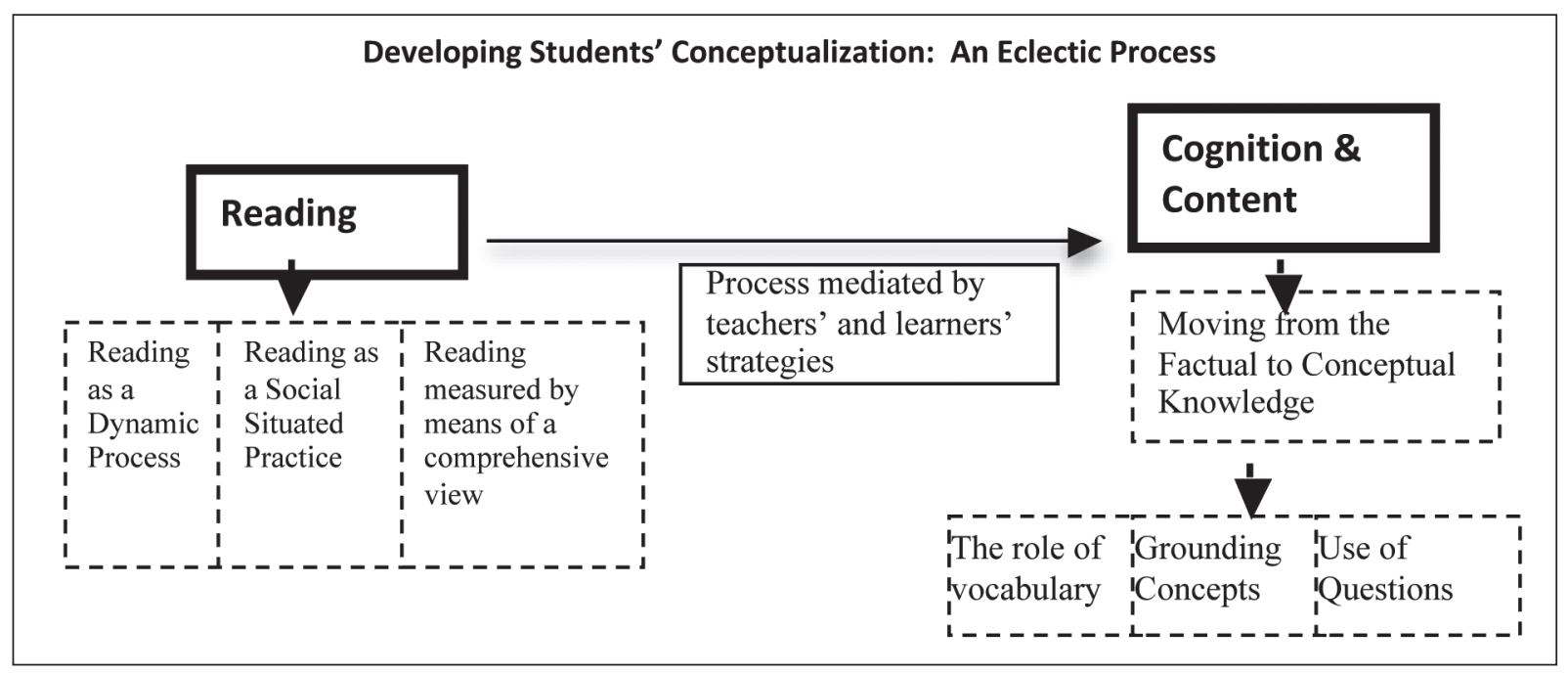

Figure 3. Implementing Intensive Reading to Promote Conceptual Understanding

Finally, the use of intensive reading helped students move from factual to conceptual knowledge as they learned key vocabulary, used questions to guide their reading process, related what they read to what they already knew, and became active participants of their reading process. Even though students are expected to become autonomous learners, fifth graders (the target population of this study) required guidance on how to effectively approach a text. The reading process becomes then a dynamic process enhanced by both teachers' and learners' strategies; the result is students' understanding of science concepts.

\section{Discussion}

When teaching a content subject, the teacher cannot overlook the fact that the main goal is to achieve conceptual understanding. Therefore, one of the main elements to consider when implementing intensive reading is the role of content and how the content-teacher should consider language goals, learning/thinking skills goals, and content goals (Coyle et al, 2010). It is the teacher's responsibility to promote different activities before and after students read a given text (i.e. sharing in pairs, making a summary, asking questions, listening to their peers' point of view) to push learners to ask, inquire, and get to know more about what they are reading. Reading 
is indeed a powerful input, which according to Gagne's (1985) Information Processing Theory, needs to be deciphered to make sense out of it. In addition to considering the students as active participants of their reading process, the teacher also needs to re-define the vision $\mathrm{s} / \mathrm{he}$ has about reading. These two previous elements have been also mentioned by Navarro (1987) who argues that the main reading comprehension difficulty lies with how the student and the teacher approach reading.

When reading has the purpose of increasing students' knowledge and promoting students apprehension of science concepts it needs to be grounded, that is to say, combined with handson activities, videos, pre-reading activities, and post-reading activities. The science classroom needs to reflect an interactive learning experience. Therefore, reading can no longer be reduced to reading a textbook and answering the questions at the end of the chapter; reading needs to be seen as a dynamic endeavor that promotes students' active role. In other words, reading needs to be seen as a flexible, interactive, and reflective process.

During this study reading emerged as a social situated practice; reading is more meaningful to students when they are able to share what they read. Even though a tension exists between reading as a personal process and reading as a process mediated by interactions among learners, students feel this "urge" to communicate and reading practices should take into account the particular needs of this new generation of learners.

Regarding how to measure reading, many authors have pointed out that reading is an invisible act quite challenging to measure (Eskey, 2005; Condemarín, 1981). However, using different types of tests to analyze to what extent students are developing reading comprehension skills may be useful. Teachers sometimes can get biased if just one type of test is used over and over. There is an ongoing controversy regarding what the cloze test really measures. According to Sadeghi's investigation (2008), cloze procedures do not measure reading comprehension. One of the main arguments of this author is that researchers have adopted cloze tests as valid instruments as a result of correlations made between cloze tests and other traditional tests. However, those correlations show moderate coefficients -as is the case in this study for the students' scores on both tests. In addition, this researcher highlights the fact that it is possible to have an overall understanding of a paper, but not be able to "predict a single word in that language". Adding to this view, Artola (1991) refers to cloze procedure as one that measures "psycholinguistic strategies" such as syntactic and semantic strategies. According to the results obtained in the present study, cloze procedures attempt to measure a linguistic ability rather than overall understanding. As Sadeghi (2008) pointed out, there are some students with low linguistic ability who can still make meaning out of a text. Therefore, the teacher needs to carefully analyze what the test results mean and provide the learner with different alternatives to measure the same construct.

The quantitative analysis shows that there are different variables besides the linguistic ability that affect the reading comprehension process. The qualitative analysis shows that one of these variables corresponds to the teachers' and learners' strategies. In this regard, Chavez (1897) in his research study about pedagogical strategies to increase the reading comprehension of eleventh graders, concluded that students should be trained in the use of those strategies to maximize results. In fact, as this author also points out, reading problem difficulties have been 
associated to the fact that students do not know how to read because they have not been taught. Goodman (1996) also supports this finding in his view of reading as a socio-psycholinguist transactional model, where he argues that "reading demands an explicit decision about what strategies and schemes are to be activated" (p. 54). The results of the present study also show the importance of modeling the activities and explicitly teaching reading strategies.

Finally, as students move from factual to conceptual knowledge three main points should be kept in mind: a) the role of vocabulary, b) grounding concepts, and c) the use of questions. Navarro (1987) suggests that reading comprehension should move from "recognizing $\mathcal{E}$ deciphering" (p. 29) to "construction of meaning". Throughout this study the use of questions to guide students' reading comprehension process was fundamental, and as Navarro (1987) points out, using questions helps learners start constructing meaning as they are pushed to make hypotheses and later on, accept or reject them. The teacher emerges then as a facilitator.

\section{Conclusions}

Reading needs to be approached as an interactive process that is embedded in meaningful activities addressed to challenge thinking. Learners enjoy working with others, sharing their ideas, asking questions, and probing whether their hypotheses are valid. Therefore, reading practices should be adapted to new learning and teaching trends; reading should not take place in isolation and should be complemented by pre-reading and post-reading activities aimed at developing highorder and low-order thinking skills.

Measuring reading implies a comprehensive view not only of reading but also of measuring. Different types of tests should be combined to guarantee that judgments about students' reading comprehension are valid and reliable. Quantitative results help the teacher know both the performance of the group by finding the mean or median and the variability by finding the range or standard deviation. These two statistical measurements are complementary and should be taken into account by every teacher as the quality of education is measured through high scores and low variability.

Students' training in new strategies such as organizing information, understanding a paragraph, or summarizing key information is required if their reading is to be successful. Students' learning process should be monitored and the teacher needs to model what s/he expects students to do. During this process, listening to students is beneficial to the learning environment and the students' learning process, as they need to be recognized as valid interlocutors.

Deciphering information implies approaching a text from different perspectives so that meaning is constructed. Asking students to read a text two or three times, each with a different focus was proven to be effective if students have a specific purpose, key vocabulary is previously known, and questions guide the students' reading process.

The CLIL framework highlights the fact that language improvement is derived from content-driven classes where language strategies have been incorporated. This study shows that students' are better able to use the language as a result of taking into account both language goals and content goals when planning the lessons. The strategies used for the purpose of scaffolding the students' language process were eliciting key vocabulary, reading with a purpose in mind, taking notes, and using graphic organizers to account for science concepts. However, it is important to mention that this study had a greater impact on the students' reading comprehension as a dynamic and interactive process than on the students' linguistic competence. 
Fostering students' content development in a science class through reading implies a) a view of reading as a dynamic and social situated practice, b) the use of hands-on activities and cooperative work to make reading meaningful, c) the explicit use of different reading strategies, and d) a process structured and scaffolded by the teacher.

The CLIL framework has proven to be effective in bilingual settings. The results of this research highlight the strengths of this framework and encourage teachers to take into account the principles of language, cognition, communication, and culture to structure practices that favor the development not only of language and content goals but also of skills and strategies that help learners move from low-order to highorder thinking.

\section{References}

Artola, T. (1991). El procedimiento cloze: una revisión general. Revista Complutense de Educación 2.1. (1991): 69 -81. Versión PDF.

Atorresi, A. (2009). Aportes para la enseñanza de la lectura, SERCE Segundo Estudio Regional Comparativo y Explicativo. Chile: UNESCO.

Auerbach, C. F. (2003). Qualitative Data: An Introduction to Coding and Analysis. New York : NYU press.

Bloom, B. (1971). Taxonomía de los Objetivos de la Educación. Buenos Aires: El Ateneo Editorial.

Brown, H. D. (2004). Language Assessment Principles and Classroom Practices. White Plains, NY: Pearson Education.

Burns, A. (1999). Collaborative action research for English language teachers. Cambridge: Cambridge University Press.

Burns, A. (2010). Doing Action Research in English Language Teaching. New York: Routledge.

Condemarín, M. Evaluación de la Comprensión Lectora. Lectura y Vida 2.2 1981: 5-16.

Chatal, R. (2001). Diagnostic and Instructional Uses of the Cloze Procedure. The Nera Journal, 37 (1), 3-6.
Chávez, V. (1987). Estrategias pedagógicas para incrementar la comprensión lectora en grado décimo del Colegio San José de Gualmatán. Pasto, Colombia: Universidad Externado de Colombia.

Coyle, D. (2005). Planning Tools for Teachers. Retrieved August $21^{\text {st }}, 2010$ from http://www.slideshare.net/ gorettiblanch/theoretical-clil-framework

Coyle, D., Hood, P., \& Marsh, D. (2010). CLIL Content and Language Integrated Learning. United Kingdom: Cambridge University Press.

Eskey, D. (2005). Reading in Second Language. In Hinkel (Ed.) Handbook of Research in Second Language Teaching and Learning.

Gagné, E. D. (1985). La Psicología Cognitiva del Aprendizaje Escolar. Traducción de Paloma Linares. Madrid: Visor Distribuciones, S.A.

Goodman, K. (1996) La lectura, la escritura y los textos escritos: una perspectiva transaccional sociopsicolingüística. Revista Textos en contexto II (1996): 9 - 68.

Hall, M. \& Austin, T. (2004). Content-Based Second Language Teaching and Learning. United States: Pearson Education, Inc.

Hedgcock, J. \& Ferris, D. (2009). Teaching Readers of English. New York: Routledge.

Lankshear, C. \& Knobel, M. (2004). Teacher Research: from Design to Implementation. New York: Open University Press.

Mehisto, P., Marsh, D., \& Frigols, M. (2008). Uncovering CLIL. China: Macmillan Publishers Limited.

Mills, G. (1999). Action Research: A guide for the Teacher Researcher. Prentice

Navarro, M. (1987). Elementos para formular una teoría sobre el proceso de comprensión de lectura. Trabajo de Grado para el título Magister en Educación. Bogotá, Colombia: Universidad de la Sabana.

Nation, P. (2004). Vocabulary Reading and Intensive Reading. EA Journal (21) 2: 20-29.

Nutall, C. (1996). Teaching Reading Skills in a Foreign Language. Great Britain: Heineman.

Sadeghi, K (2008). Measuring Reading Comprehension: The Judgmental Validity of Cloze Procedure. International Journal of American Linguistics 11.2: $115-130$. 
Sagor, R. (2005). The Action Research Guidebook. Thousand Oaks, CA: Corwin Press.

Sejnost, R. (2007). Reading and Writing across Content Areas. Thousand Oaks, CA: Corwin Press.

Sijtsma, K. \& Molenaar, I. (2002). Introduction to Nonparametric Item Response Theory. London: Sage Publications.
Snow, M., Met, M., \& Genesse, F. (1989). A Conceptual Framework for the Integration of Language and Content in Second/Foreign Language Instruction. TESOL Quarterly, (23) 2 : 201 - 217.

\section{THE AUTHOR}

ALETHIA BOGOYA HOLDS a bachelors degree in Engineering from Universidad Nacional and a masters degree in English Language Teaching from Universidad de La Sabana. She is working at Rochester School as a math teacher and middle-school math curriculum assisstant. Two years ago she began researching on how to integrate language and content. 


\section{Appendix A.}

\section{Student's Artefacts: Graphic Organizer, Week 7}

\begin{tabular}{|c|c|c|}
\hline \multicolumn{3}{|r|}{ ROCHESTER SCHOOL - FIFTH_GRADE - READING PROJECT: ACTIVITY 5} \\
\hline Name. & Date $f(r-5-28$ & \\
\hline \multicolumn{3}{|c|}{ Directions: After reading the pages given by your teacher, complete the following graphic organizer. } \\
\hline CONTENT: CONCEPTS & LANGUAGE: VERBS & $\begin{array}{l}\text { Using the words on the two previous colums (at least four), } \\
\text { write down a } 40 \text {-word paragaph explaining how a wave is } \\
\text { produced and how it transfers energy. Please highlight the } \\
\text { words you use from the previous colums. }\end{array}$ \\
\hline $\begin{array}{l}\text { Force } \\
\text { Motion } \\
\text { Wave } \\
\text { Mechanical Wave } \\
\text { Medium }\end{array}$ & $\begin{array}{l}\text { Apply } \\
\text { Push } \\
\text { Pull }\end{array}$ & 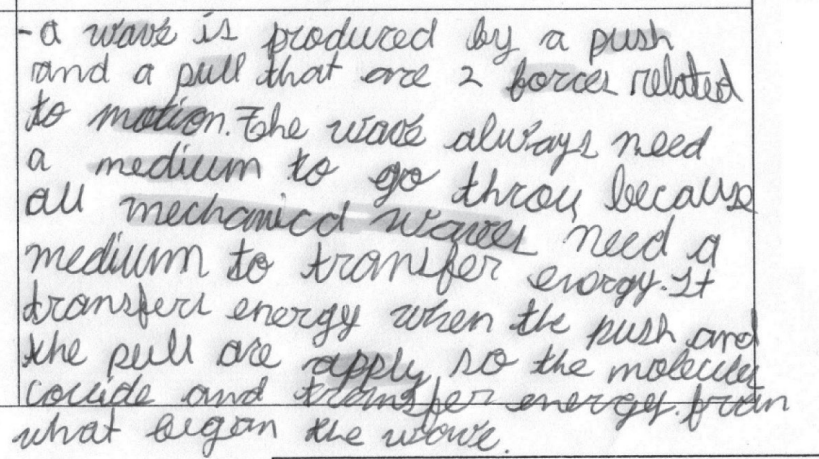 \\
\hline & & 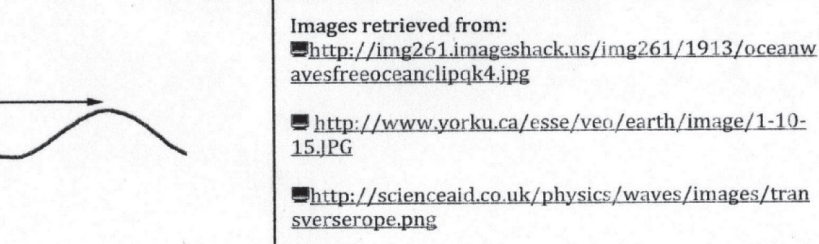 \\
\hline
\end{tabular}

\section{Appendix B.}

\section{Cloze Test used as a Pre-test}

Name

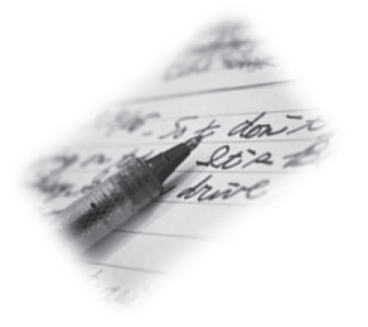

Directions: some words have been deleted from the following passage; your job is to find out the missing words. Write down one single word per each space.

Please, look over the entire passage before beginning. 


\section{MATTER CAN CHANGE FROM ONE STATE TO ANOTHER ${ }^{1}$}

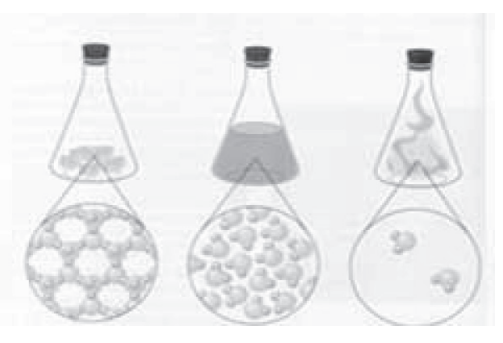

Matter is commonly found in three states: solid, liquid and gas. A solid has a also has a volume but takes the of its container $A$ volume and a fixed A liquid __always exists in one _ these states, but it has neither a fixed nor a fixed shape.

When matter changes from state to another, the change from one state to all the same basic substance. water turns into ice itself does not change. ice, and water vapor do not change. What are the arrangement of the water vapor, the water themselves

Changes in state are physical changes because changes in state do not change the basic substance.

\section{Appendix C.}

\section{CARI Test used as a Pre-Test, Sections 2 \& 3}

\section{CHANGES OF STATE ARE PHYSICAL CHANGES}

SECTION II - VOCABULARY2

1. What is the difference between melting and freezing?

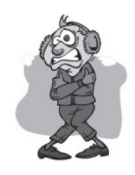

2. Define boiling point

3. Give an example of condensation

\footnotetext{
1 Excerpt taken from the textbook McDougal Littell 1. Unit: Matter \& Energy, page 50. Images taken from http://www.flickr.com/photos/mcvay728/107652337/ http://idahoptv.org/dialogue4kids/season7/matter/images/matter2.jpg

2 Images taken from http://fightingbrimley.files.wordpress.com/2008/12/freezing man.jpg http://images.clipartof.com/small/14157-Hot-Water-Boiling-In-A-Pot-Food-Clipart-Illustration.jpg http://myweb.cwpost.liu.edu/vdivener/notes/solid-liquid-gas.gif
} 


\section{SECTION III - TEXT EXPLICIT AND TEXT IMPLICIT INFORMATION}

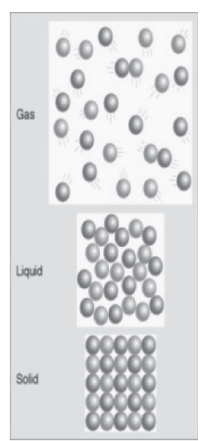

1. Read paragraph 2 under the section Melting:

a. Describe the motion of particles in a solid state

b. What is the cause of matter changing from solid to liquid?

c. What happens when molecules vibrate faster?

2. What happens to the liquid particles when matter changes from liquid to solid? (page 52)

a. Describe the movement of particles in a liquid as it evaporates

b. How does adding energy to matter by heating it affect the energy of its particles? 